\title{
Erratum
}

\section{Patterns of food acquisition in Brazilian households and associated factors: a population-based survey - Erratum}

\author{
Dirce M Marchioni, Rafael M Claro, Renata B Levy and Carlos A Monteiro
}

First published online 16 May 2011

doi:10.1017/S1368980011000486 Published by Cambridge University Press, 13 April 2011

On page 1586 in the Abstract

Conclusions: Dietary patterns described here suggest that policies and programmes to promote healthy eating need to consider that healthy and non-healthy foods may be integral in the same pattern.

replace with

Conclusions: Dietary patterns described here suggest that policies and programmes to promote healthy eating need to consider that healthy and non-healthy food may be integrated within the same pattern.

On page 1591, column 2, lines 9-15

Besides the fact that knowledge of the sociodemographic characteristics related to the patterns might help identify groups for target campaigns and interventions, the dietary patterns described here suggest that food programmes to promote healthy eating need to consider the fact that healthy and non-healthy foods may be integral in the same pattern.

replace with

Besides the fact that knowledge of the sociodemographic characteristics related to the patterns might help identify groups for target campaigns and interventions, the dietary patterns described here suggest that policies and programmes to promote healthy eating need to consider that healthy and non-healthy food may be integrated within the same pattern.

\section{Reference}

Marchioni DM, Claro RM, Levy RB \& Monteiro CA. Patterns of food acquisition in Brazilian households and associated factors: a population-based survey. Public Health Nutrition Published by Cambridge University Press, 13 April 2011. doi:10.1017/ S1368980011000486. 